\title{
Review of optical design for vehicle forward lighting based on white LEDs
}

\author{
Ching-Cherng Sun, ${ }^{\text {a,b }}$ Chi-Shou Wu, ${ }^{\text {a,* }}$ Yong-Sheng Lin, ${ }^{a}$ Yi-Jou Lin, ${ }^{a}$ \\ Cheng-Yan Hsieh, ${ }^{a}$ Shih-Kang Lin, ${ }^{a}$ Tsung-Hsun Yang $\odot,{ }^{a}$ \\ and Yeh-Wei Y $\mathbf{u}^{\mathrm{a}}$ \\ ${ }^{a}$ National Central University, Department of Optics and Photonics, Chung-Li, Taiwan \\ ${ }^{b}$ National Yang Ming Chiao Tung University, Department of Electrophysics, \\ Hsin-Chu, Taiwan
}

\begin{abstract}
We introduce a current development in optical design for vehicle forward lighting based on solid-state lighting, in particular, phosphor-converted white LEDs. The vehicles include bicycles, bikes, and automobiles. Although the requirements regulating different vehicles are different, the low beam always requires a high-contrast cutoff line. Three optical design approaches are discussed; these include a projection lens incorporated with a baffle or beam shaper, multisegment reflectors, and complex lenses. A new design approach called light field management technology for the multisegment reflector is introduced. In addition, the possible related manufacturing errors and the robustness of different optical approaches are analyzed. Finally, we introduce three approaches to adaptive forward lighting that provide a driver with brighter and clearer vision without inducing glare to people on the roadway. The application of video projection technology to roadway illumination could be a trend of vehicle forward lighting based on solid-state lighting. (C) The Authors. Published by SPIE under a Creative Commons Attribution 4.0 Unported License. Distribution or reproduction of this work in whole or in part requires full attribution of the original publication, including its DOI. [DOI: 10.1117/1.OE.60.9.091501]
\end{abstract}

Keywords: phosphor-converted white LED; forward lighting; headlamp; solid-state lighting.

Paper 20210744SSV received Jul. 15, 2021; accepted for publication Aug. 11, 2021; published online Aug. 24, 2021.

\section{Introduction}

In general, a white LED is made with a blue die covered with yellow phosphor to perform downconversion, so it is called a phosphor-converted white LED (simplified pcW-LED). ${ }^{1-10}$ PcW-LEDs have been extensively applied to general lighting and special lighting. So far, there seems to be no serious limit on the LED light sources except the flux density. Thus, optimizing the usage of an LED or pcW-LED is an important topic in general. Among various applications of pcW-LED, automotive forward lighting is significant owing to the application in vehicles that require long life, quick response, low cost, compact size, low power, and adjustable form factor. ${ }^{11-13}$ Such characteristics are all equipped in pcW-LEDs. Before 2010, the barrier to applying a pcW-LED in vehicle headlamps was the cost and the luminous exitance. The former was overcome by mass production and the latter by luminous efficiency that exceeded $100 \mathrm{~lm} / \mathrm{W} .{ }^{14}$ Even with a luminous efficacy below $100 \mathrm{~lm} / \mathrm{W}$, in 2007, the world's first LED headlamp was equipped in a luxury car, ${ }^{15}$ and this was the starting point of a new era of LED for automotive forward lighting. It means that the optical properties of pcW-LEDs met the requirements of a headlamp owing to their advantages in luminous efficiency and exitance. Such properties enable pcW-LEDs suitable for vehicle forward lighting for trains, cars, trucks, motorcycles, and bicycles. ${ }^{16-23}$ The vehicle forward light, which is also called the headlamp, is used to illuminate all objects on the roadway for a driver. The headlamp must provide sufficient illumination to the objects while avoiding inducing glare to the drivers or pedestrians on the roadway. Thus, the light pattern of a headlamp is defined in certain regulations. Figure 1 shows the light patterns in the ECE regulation, ${ }^{24,25}$ where the light patterns can be divided into two parts. The first,

*Address all correspondence to Chi-Shou Wu, deniswu1024@gmail.com 


\begin{tabular}{|c|c|c|c|c|c|}
\hline & $\begin{array}{c}\text { ECE } \\
\text { regulation }\end{array}$ & $\begin{array}{l}\text { Cut-off line } \\
\text { requirement }\end{array}$ & $\begin{array}{c}\text { Contrast } \\
\text { ratio }\end{array}$ & $\begin{array}{l}\text { Hot Spot } \\
\text { requirement }\end{array}$ & $\begin{array}{l}\text { Light pattern } \\
\text { at } 25 \mathrm{~m}\end{array}$ \\
\hline $\begin{array}{c}\text { Daytime } \\
\text { running } \\
\text { light }\end{array}$ & $\begin{array}{l}\text { ECE } \\
\text { R87 }\end{array}$ & No & & $400 \mathrm{~cd}$ & $20^{\circ}$ \\
\hline Fog lamp & $\begin{array}{l}\text { ECE } \\
\text { R19 }\end{array}$ & Yes & 1.5 & $1.5 \mathrm{lux}$ & $2000 \mathrm{~cm}$ \\
\hline $\begin{array}{l}\text { Motor- } \\
\text { low beam }\end{array}$ & $\begin{array}{l}\text { ECE } \\
\text { R113 }\end{array}$ & Yes & 4.3 & $3 \operatorname{lux}$ & $\underset{450 \mathrm{~cm}}{\longrightarrow} 100 \mathrm{~cm}$ \\
\hline $\begin{array}{c}\text { Motor- } \\
\text { high beam }\end{array}$ & $\begin{array}{l}\text { ECE } \\
\text { R113 }\end{array}$ & No & & $32 \operatorname{lux}$ & $\stackrel{450 \mathrm{~cm}}{\longrightarrow} 100 \mathrm{~cm}$ \\
\hline $\begin{array}{c}\text { Auto- } \\
\text { low beam }\end{array}$ & $\begin{array}{l}\text { ECE } \\
\text { R112 }\end{array}$ & Yes & 30 & $16 \operatorname{lux}$ & $\rightarrow 85 \mathrm{~cm}$ \\
\hline $\begin{array}{c}\text { Auto- } \\
\text { high beam }\end{array}$ & $\begin{array}{l}\text { ECE } \\
\text { R112 }\end{array}$ & No & & $48 \operatorname{lux}$ & $\underset{450 \mathrm{~cm}}{\longrightarrow} 100 \mathrm{~cm}$ \\
\hline
\end{tabular}

Fig. 1 A comparison of light patterns in ECE regulation.

including the low beam and the fog beam, requires a high-contrast cutoff line. The bright zone is below the cutoff line, and the dark zone is above the cutoff line. The principle of the cutoff line is to protect people by decreasing glare on the roadway. The second, including the high beam and the daytime running light, is without the cutoff line. The high beam provides clear vision to a driver but induces serious glare to people on the roadway, so it can be used only when no people are in front of the driver. The daytime running light is used to provide a clear signal of the car on the roadway, so its function is as a signal rather than an illuminator. In this review paper, we focus on the study of the optical design of forward lighting excluding the daytime running light.

\section{Regulations}

Before the introduction of the optical design, a review of the regulations is necessary. In this paper, we focus on ECE regulations for automobiles and bikes and K-mark regulations for bicycles. ${ }^{26}$ Figures 2 and 3 show the requirements of the low beam and high beam in the regulation.

(a)

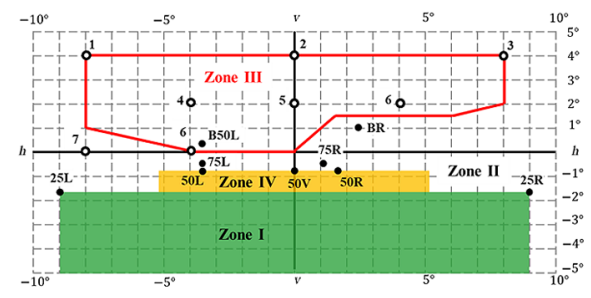

(b)

\begin{tabular}{|c|c|c|c|c|c|c|c|c|}
\hline Test point & \multicolumn{7}{|c|}{ Angular coordinates [degrees] } & $\begin{array}{l}\text { Required luminous } \\
\text { intensity [cd] }\end{array}$ \\
\hline B $50 \mathrm{~L}$ & \multicolumn{7}{|c|}{$0.57 \mathrm{U}, 3.43 \mathrm{~L}$} & $<350$ \\
\hline BR & \multicolumn{7}{|c|}{$1.0 \mathrm{U}, 2.5 \mathrm{R}$} & $<1750$ \\
\hline $75 \mathrm{R}$ & \multicolumn{7}{|c|}{$0.57 \mathrm{D}, 1.15 \mathrm{R}$} & $>10100$ \\
\hline $75 \mathrm{~L}$ & \multicolumn{7}{|c|}{$0.57 \mathrm{D}, 3.43 \mathrm{~L}$} & $<10600$ \\
\hline $50 \mathrm{~L}$ & \multicolumn{7}{|c|}{$0.86 \mathrm{D}, 3.43 \mathrm{~L}$} & $<13200$ \\
\hline $50 \mathrm{R}$ & \multicolumn{7}{|c|}{$0.86 \mathrm{D}, 1.72 \mathrm{R}$} & $>10100$ \\
\hline $50 \mathrm{~V}$ & \multicolumn{7}{|c|}{$0.86 \mathrm{D}, 0$} & $>5100$ \\
\hline $25 \mathrm{~L}$ & \multicolumn{7}{|c|}{$1.72 \mathrm{D}, 9.0 \mathrm{~L}$} & $>1700$ \\
\hline $25 \mathrm{R}$ & \multicolumn{7}{|c|}{$1.72 \mathrm{D}, 9.0 \mathrm{R}$} & $>1700$ \\
\hline \multirow{3}{*}{ Any point in zone III } & \multicolumn{7}{|c|}{ Bounded by the following coordinates } & \multirow{3}{*}{$<625$} \\
\hline & $8 \mathrm{~L}$ & $8 \mathrm{~L}$ & $8 \mathrm{R}$ & $8 \mathrm{R}$ & $6 \mathrm{R}$ & $1.5 \mathrm{R}$ & $\mathrm{V}-\mathrm{V}$ & \\
\hline & $1 \mathrm{U}$ & $4 \mathrm{U}$ & $4 \mathrm{U}$ & $2 \mathrm{U}$ & $1.5 \mathrm{U}$ & $1.5 \mathrm{U}$ & H-H & \\
\hline Any point in zone IV & \multicolumn{7}{|c|}{$086 \mathrm{D}$ to $1.72 \mathrm{D}, 5.15 \mathrm{~L}$ to $5.15 \mathrm{R}$} & $>2500$ \\
\hline Any point in zone I & \multicolumn{7}{|c|}{$1.72 \mathrm{D}$ to $4 \mathrm{D}, 9 \mathrm{~L}$ to $9 \mathrm{R}$} & $<2 \times \mathrm{I}_{30 \mathrm{~L}}$ or $2 \times \mathrm{I}_{30 \mathrm{R}}$ \\
\hline $1+2+3$ & \multicolumn{7}{|c|}{$(4 \mathrm{U}, 8 \mathrm{~L})+(4 \mathrm{U}, 0)+(4 \mathrm{U}, 8 \mathrm{R})$} & $>190$ \\
\hline $4+5+6$ & \multicolumn{7}{|c|}{$(2 \mathrm{U}, 4 \mathrm{~L})+(2 \mathrm{U}, 0)+(2 \mathrm{U}, 4 \mathrm{R})$} & $>375$ \\
\hline 7 & \multicolumn{7}{|c|}{$0,8 \mathrm{~L}$} & $>65$ \\
\hline 8 & \multicolumn{7}{|c|}{$0,4 \mathrm{~L}$} & $>165$ \\
\hline
\end{tabular}

Fig. 2 The ECE R112 regulation for the low beam. (a) The light pattern structure at $25 \mathrm{~m}$ and (b) the detailed description. 
(a)

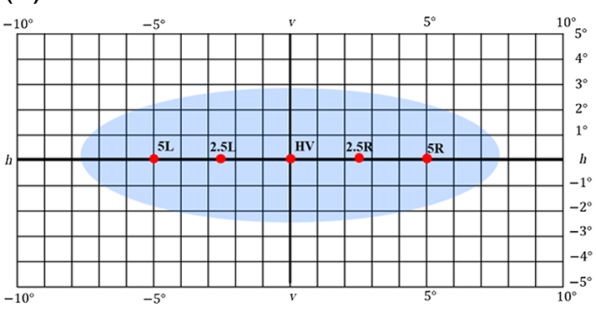

(b)

\begin{tabular}{|c|c|c|}
\hline $\begin{array}{c}\text { Test } \\
\text { point }\end{array}$ & $\begin{array}{c}\text { Angular coordinates } \\
\text { [degrees] }\end{array}$ & $\begin{array}{c}\text { Required luminous intensity } \\
\text { [cd] }\end{array}$ \\
\hline$I_{\max }$ & & $215,000>I_{\max }>40,500$ \\
\hline $\mathrm{HV}$ & 0,0 & $\geq I_{\max } \times 80 \%$ \\
\hline $\mathrm{H}-5 \mathrm{~L}$ & $0,5 \mathrm{~L}$ & $>5,100$ \\
\hline $\mathrm{H}-2.5 \mathrm{~L}$ & $0,2.5 \mathrm{~L}$ & $>20,300$ \\
\hline $\mathrm{H}-2.5 \mathrm{R}$ & $0,2.5 \mathrm{R}$ & $>20,300$ \\
\hline $\mathrm{H}-5 \mathrm{R}$ & $0,5 \mathrm{R}$ & $>5,100$ \\
\hline
\end{tabular}

Fig. 3 The ECE R112 regulation for the high beam. (a) The light pattern structure at $25 \mathrm{~m}$ and (b) the detailed description. ${ }^{24,25}$

The ECE R112 regulation is for automobiles. Without the glare issue, the objective of the high beam is to provide clear vision to a driver without any restriction, so the high beam pattern is an ellipse. In comparison with the high beam, the light pattern of the low beam is much more complicated because of the cutoff line. Above the cutoff line, the dark zone is required to provide limited illumination to avoid glare. Below the cutoff line, the bright zone must be bright enough with the light distribution covering the important viewing zone for the driver. So the light pattern is not symmetrical and must be more widely spread along the horizontal direction than the vertical direction. Figure 4 shows the regulation of ECE R113 class B, which is for bikes, including e-bikes. ${ }^{24,25}$ Figures 4(a) and 4(b) show the detailed instructions for the low beam. Different from the regulation for an automobile, the light pattern of the low beam for a bike is symmetrical along the horizontal direction, but the cutoff line is required to provide high linearity and high contrast. The linearity means that the cutoff line shall not exceed the vertical range formed by two horizontal lines that are situated from 3 deg right to 3 deg left of the V-V line at 0.2 deg for class B. The luminous intensity in the bright zone is smaller than that in an automobile, but the lateral extension of the bright zone is similar to that in the ECE R112 regulation except without an extended ground illumination. The light pattern of the high beam is spread horizontally with less brightness required in comparison with the regulation for an automobile.

(a)

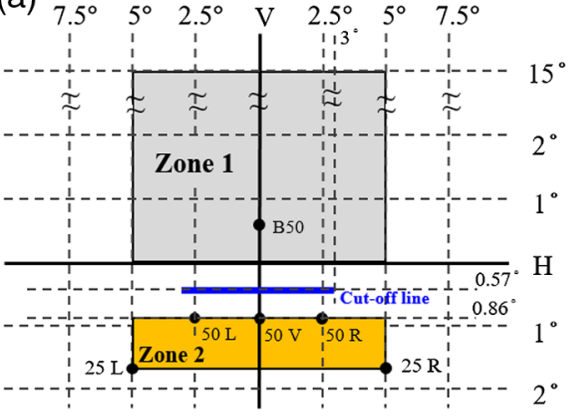

(c)

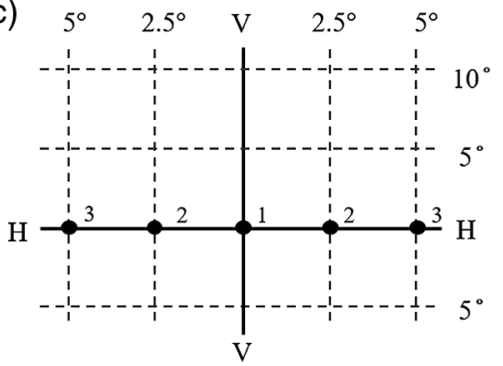

(b)

\begin{tabular}{|c|c|c|c|}
\hline & \multicolumn{2}{|l|}{ Angular coordinates (degrees) } & $\begin{array}{c}\text { Luminous } \\
\text { intensity (cd) }\end{array}$ \\
\hline Any point in zone 1 & $0^{\circ} \sim 15^{\circ} \mathrm{U}$ & $5^{\circ} \mathrm{L} \sim 5^{\circ} \mathrm{R}$ & $\leq 700 \mathrm{~cd}$ \\
\hline $\begin{array}{c}\text { Any point on line } \\
\text { 50L to 50R }\end{array}$ & $0.86^{\circ} \mathrm{D}$ & $2.5^{\circ} \mathrm{L} \sim 2.5^{\circ} \mathrm{R}$ & $\geq 1,100 \mathrm{~cd}$ \\
\hline Point 50 V & $0.86^{\circ} \mathrm{D}$ & $\mathrm{V}$ & $\geq 2,200 \mathrm{~cd}$ \\
\hline $\begin{array}{c}\text { Any point on line } \\
\text { 25L to 25R }\end{array}$ & $1.72^{\circ} \mathrm{D}$ & $5^{\circ} \mathrm{L} \sim 5^{\circ} \mathrm{R}$ & $\geq 2,200 \mathrm{~cd}$ \\
\hline Any point in zone 2 & $0.86^{\circ} \sim 1.72^{\circ} \mathrm{D}$ & $5^{\circ} \mathrm{L} \sim 5^{\circ} \mathrm{R}$ & $\geq 1,100 \mathrm{~cd}$ \\
\hline Shape of cut-off line & $\begin{array}{c}\text { Linearity within } \pm 0.2^{\circ} \text { from the } 0.57^{\circ} \mathrm{D} \text { axis. } \\
G \geq 0.13 \text { for } G=\left(\log E_{V}-\log E_{\left(\mathrm{V}+0.1^{\circ}\right)}\right)\end{array}$ \\
\hline
\end{tabular}

(d)

\begin{tabular}{|c|c|c|c|}
\hline $\begin{array}{c}\text { Test point } \\
\text { number }\end{array}$ & \multicolumn{2}{|c|}{$\begin{array}{c}\text { Angular coordinates } \\
\text { (degrees) }\end{array}$} & $\begin{array}{c}\text { Luminous } \\
\text { intensity (cd) }\end{array}$ \\
\hline 1 & \multirow{3}{*}{$\mathrm{HH}$} & VV & $\leq 16,000 \mathrm{~cd}$ \\
\hline 2 & & $2.5^{\circ} \mathrm{R}$ and $2.5^{\circ} \mathrm{L}$ & $\geq 9,000 \mathrm{~cd}$ \\
\hline 3 & & $5^{\circ} \mathrm{R}$ and $5^{\circ} \mathrm{L}$ & $\geq 2,500 \mathrm{~cd}$ \\
\hline \multicolumn{4}{|c|}{$\begin{aligned} \text { Minimum of } I_{\text {maximum }} & =20,000 \mathrm{~cd} \\
\text { Maximum of } I_{\text {maximum }} & =215,000 \mathrm{~cd}\end{aligned}$} \\
\hline
\end{tabular}

Fig. 4 The ECE R113 class B regulation. (a) The light pattern structure of the low beam at $25 \mathrm{~m}$, (b) the detailed description, (c) the check points of the high beam at $25 \mathrm{~m}$, and (d) the detailed description. ${ }^{24,25}$ 
(a)

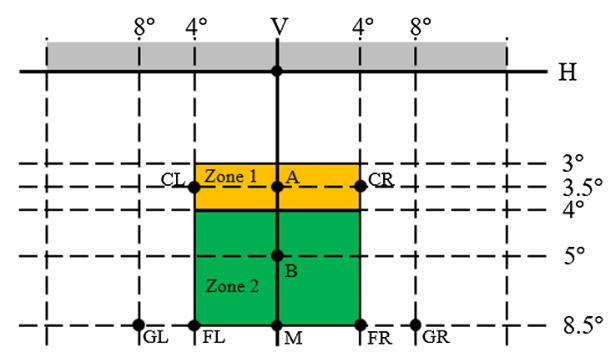

(b)

\begin{tabular}{|c|c|c|c|}
\hline Testing point & \multicolumn{2}{|c|}{$\begin{array}{c}\text { Angular coordinates } \\
\text { (degrees) }\end{array}$} & $\begin{array}{l}\text { Illuminance } \\
\text { (lux) }\end{array}$ \\
\hline \multicolumn{4}{|c|}{ Zone 1 illumination values shall be $\leq 1.2 \mathrm{E}_{\mathrm{A}}$} \\
\hline $\mathrm{A}$ & $3.5^{\circ} \mathrm{D}$ & $\mathrm{V}$ & $>201 x$ \\
\hline From $\mathrm{CR}$ to $\mathrm{CL}$ & $3.5^{\circ} \mathrm{D}$ & $4^{\circ} \mathrm{L} \sim 4^{\circ} \mathrm{R}$ & $\geq \mathrm{E}_{\mathrm{A}} / 2$ \\
\hline From $\mathrm{A}$ to $\mathrm{B}$ & $3.5^{\circ} \mathrm{D} \sim 5^{\circ} \mathrm{D}$ & $\mathrm{V}$ & $>10 \mathrm{~lx}$ \\
\hline \multicolumn{4}{|c|}{ Zone 2 illumination values shall be $\leq \mathrm{E}_{\mathrm{A}}$} \\
\hline From $\mathrm{B}$ to $\mathrm{M}$ & $5^{\circ} \mathrm{D} \sim 8.5^{\circ} \mathrm{D}$ & $\mathrm{V}$ & $>3 \mathrm{~lx}$ \\
\hline $\begin{array}{c}\text { From GL to } \\
\text { GR }\end{array}$ & $8.5^{\circ} \mathrm{D}$ & $8^{\circ} \mathrm{L} \sim 8^{\circ} \mathrm{R}$ & $>2 \mathrm{~lx}$ \\
\hline $\mathrm{HV}$ & \multicolumn{2}{|c|}{$\begin{array}{l}\text { On the } \mathrm{H}-\mathrm{H} \text { line and } \\
\text { above } \mathrm{H}-\mathrm{H} \text { line }\end{array}$} & $\leq 2 \mathrm{~lx}$ \\
\hline
\end{tabular}

(d)

\begin{tabular}{|c|c|c|c|}
\hline $\begin{array}{c}\text { Testing } \\
\text { point }\end{array}$ & \multicolumn{2}{|c|}{$\begin{array}{c}\text { Angular coordinates } \\
\text { (degrees) }\end{array}$} & $\begin{array}{c}\text { Illuminance } \\
\text { (lux) }\end{array}$ \\
\hline $\mathrm{HV}$ & $\mathrm{HH}$ & $\mathrm{VV}$ & $\geq 50 \mathrm{~lx}$ \\
\hline $\mathrm{A} 1 \& \mathrm{~A} 2$ & $\mathrm{HH}$ & $4^{\circ} \mathrm{L}$ and $4^{\circ} \mathrm{R}$ & $\geq \mathrm{E}_{\mathrm{HV}} / 2$ \\
\hline $\mathrm{A} 3$ & $3.5^{\circ} \mathrm{D}$ & $\mathrm{VV}$ & $\geq 10 \mathrm{~lx}$ \\
\hline
\end{tabular}

(c)

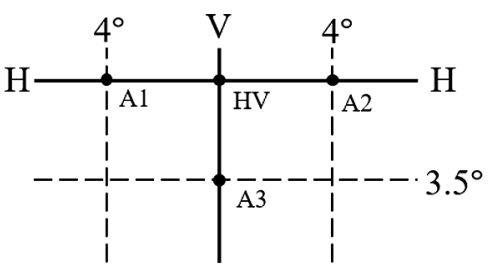

Fig. 5 The K-mark regulation. (a) The light pattern structure of the low beam at $10 \mathrm{~m}$, (b) the detailed description, (c) the check points of the high beam at $10 \mathrm{~m}$, and (d) the detailed description. $^{26}$

The headlamp is equipped not only in a bike or an automobile but also in a bicycle, which is used for transportation and health purposes. For a bicycle, the Germany regulation called the $\mathrm{K}$-mark regulation is the primary regulation, ${ }^{26}$ as shown in Fig. 5. The K-mark regulation is somewhat similar to the ECE R113 class B regulation for its lower riding speed than that of an automobile. The low beam in the K-mark regulation still requires a cutoff line but with less brightness and narrower lateral extension. However, it requires more ground illumination than that in the ECE R113 class B regulation. The high beam is similar to that in the ECE R113 class $B$ regulation, but with narrower lateral extension and less brightness.

Although the regulation of the automobile is stricter than those for the bikes and bicycles, the space to contain the headlamp in an automobile is obviously bigger than the others. The space and weight for a bicycle headlamp are always limited. In addition, a bicycle headlamp cannot consume too much electrical power, and the price must be low; thus the design for a bicycle headlamp is as complicated as that in the other vehicles.

\section{Characteristics of pcW-LEDs}

To design a headlamp with the use of pcW-LEDs, the properties of pcW-LEDs must be figured out to fit the purpose. The properties include the allowed injection current/power and the effective area of the emitting surface. In general, an LED die of $1 \mathrm{~mm} \times 1 \mathrm{~mm}$ is used to load $3 \mathrm{~W}$ of electrical power. Higher power requirements need a larger emitting area of the LED die. However, a large emitting area has a large etendue, which is a geometrical factor that is related to the formation of the cutoff line. The smaller the etendue is, the sharper the cutoff line is. ${ }^{27}$ Owing to the inherent scattering characteristic of the phosphor, the emitting surface of a pcWLED looks like a Lambertian surface. ${ }^{28}$ Therefore, etendue (U) is written as ${ }^{29-34}$

$$
U=A n^{2} \iint \cos \theta \mathrm{d} \Omega=\pi n^{2} A,
$$

where $n$ is the refractive index of medium, $A$ is the emitting area, the solid angle of the light cone $d \Omega=2 \pi \sin \theta \mathrm{d} \theta$, and $\theta$ is the propagation angle of the light cone shown in Fig. 6. From Eq. (1), the etendue is a function of the emitting area. Therefore, the power management of the light 


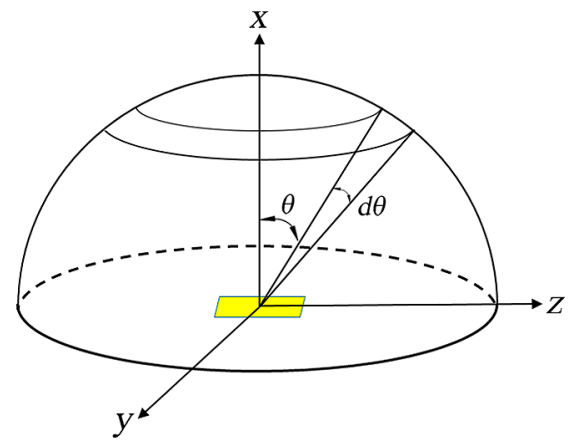

Fig. 6 The geometry for the integration of etendue.

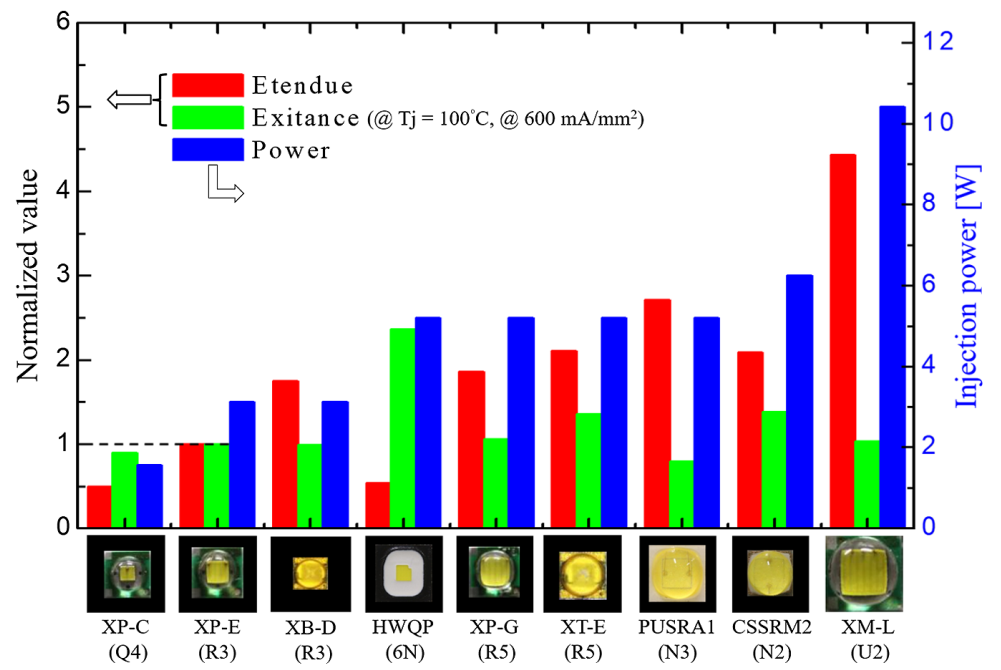

Fig. 7 A comparison among commercial pcW-LEDs. The etendue and exitance are normalized based on the value by XP-E(R3).

source relates to the die area and the pcW-LED number for a headlamp. This means that the injection power and the die area are two factors, but they are not independent of each other. To have a clearer picture of the light source, we add a parameter called luminous exitance, ${ }^{35}$ which is the ratio between the luminous flux and the emitting area, and it equals flux density. The larger the exitance is, the smaller the etendue is. Figure 7 shows a comparison among several commercial pcW-LEDs by Osram ${ }^{36}$ or Cree. ${ }^{37}$ The comparison shows that the pcW-LED with larger luminous flux could always have a larger emitting area, so the etendue is larger. Thus, the etendue and the luminous exitance should be carefully considered. In a bicycle headlamp, the volume and weight are limited, so there is less capacity to contain a large heat dissipater and optics. Therefore, the etendue and luminous exitance are more important than the luminous flux in designing a low-power bike or bicycle headlamp.

\section{Optical Design Approaches}

The design of a vehicle should follow the requirement of the appointed regulation, and then choosing the most appropriate pcW-LED by following the analysis shown in Fig. 7 is the top task. Then, the designer has to choose the suitable optical approach to form the light pattern in considering the form factor, injection power, and cost. A design flow chart is shown in Fig. 8 . After the design, the precise light source model ${ }^{28,38,39}$ and accurate Monte Carlo ray-tracing simulation must be done to check if the simulated design meets the regulation. The final step is to make a prototype of the module and to examine the performance according to the regulation. 


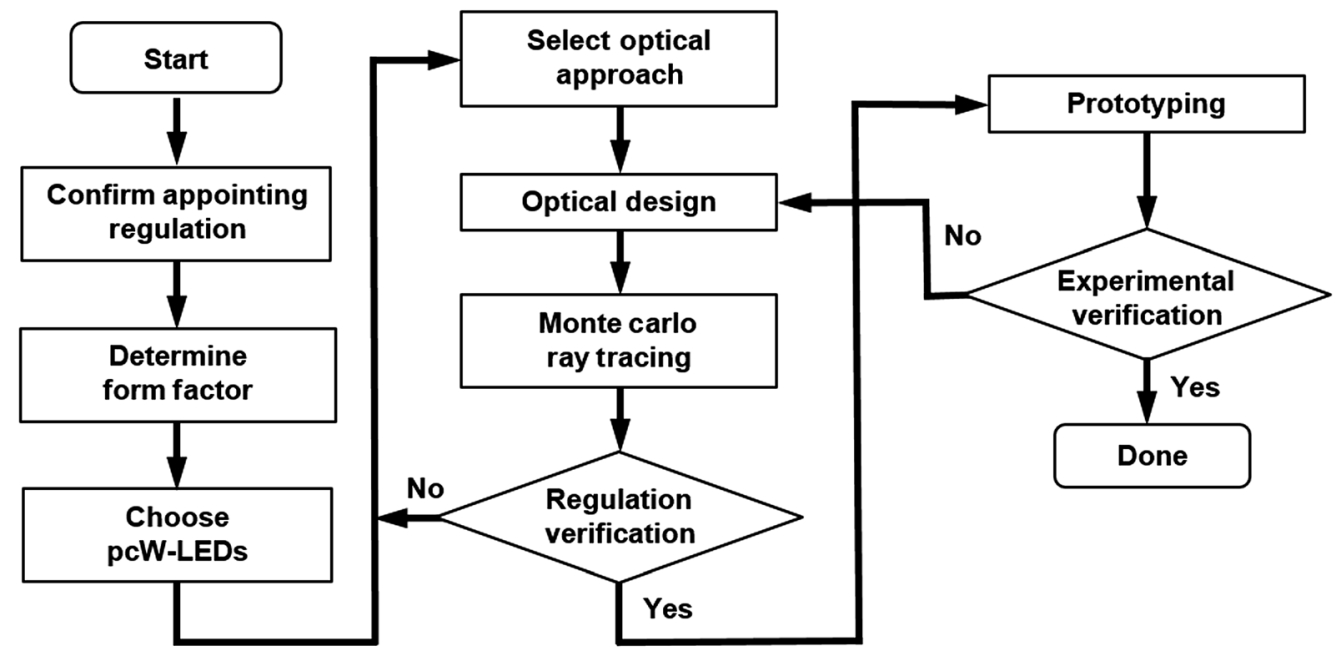

Fig. 8 Flowchart of the design procedure.

If there is something wrong, the optical design and the manufacture of the prototype must be checked until the experiment shows that the observed light pattern meets the regulation.

The optical design of the headlamp can be divided into two categories. The first is for those with a cutoff line, and the second is those without a cutoff line. The design for the high beam and the daytime running light is more straightforward. A lens or a mirror to shape the beam into an ellipse with sufficient luminous intensity is applicable. Figure 9 shows an example using a reflector. The multisegment reflector shown in Fig. 9 is useful for shaping the projection light. The principle of optical design is to adjust the divergent angle to meets the requirement. Since the light pattern is an ellipse, the divergent angle along the horizontal axis should be larger than that along the vertical axis. Such a light pattern is easy to achieve through a reflector or a compound lens such as a total internal reflection (TIR) lens. ${ }^{40-45}$

The design becomes complicated when designing a low beam, regardless of the vehicle type. The most difficult part is to form the high-contrast cutoff line. To summarize the available and

(a)

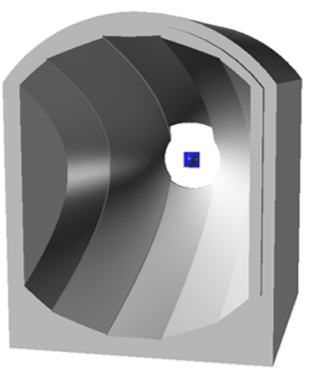

(c)

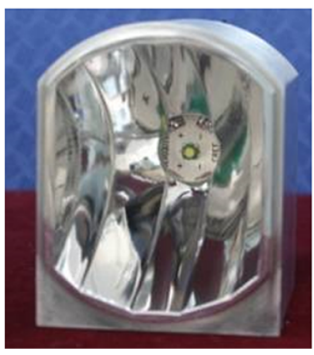

(b)

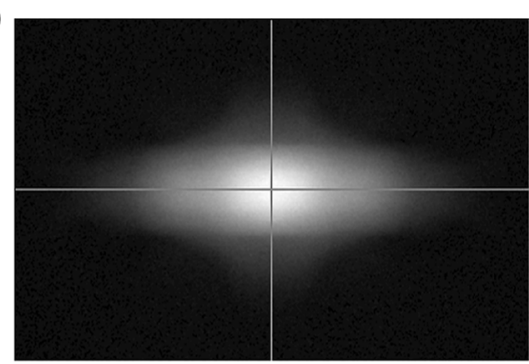

(d)

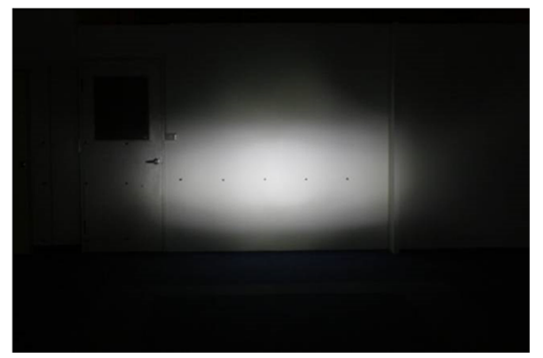

Fig. 9 A design for meeting the high beam of the ECE R112 regulation. (a) The designed geometry, (b) the simulated light pattern at $25 \mathrm{~m}$, (c) the prototype, and (d) the light pattern observed in the experiment. 
(a)
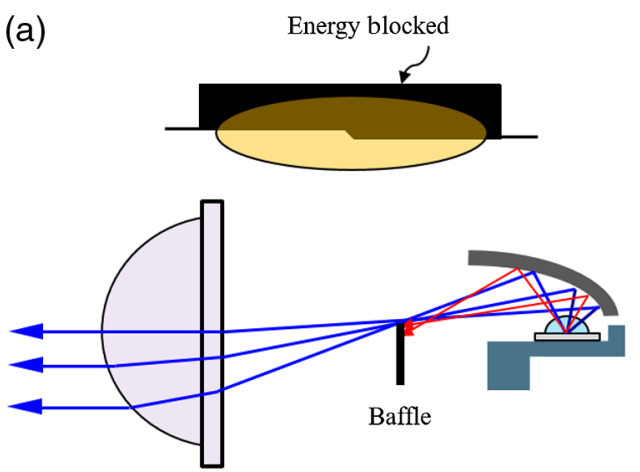

(b)
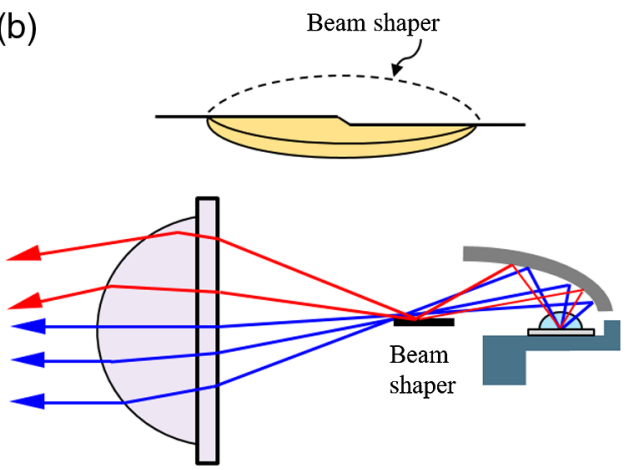

Fig. 10 The design with projection lens: (a) with a baffle and (b) with a beam shaper. ${ }^{76,77}$

effective design approaches, here we divide the approaches into three types. The first is a projection system with a beam shaper, ${ }^{42,46-50}$ the second is a multisegment reflector, ${ }^{51-56}$ and the third is a complex lens including a freeform lens. ${ }^{57-75}$ Figure 10 shows the basic concept of the projection system with a beam shaper. ${ }^{76}$ The traditional approach is to put the light source at one of the focuses of the elliptical reflector. Then, the elliptical reflector focuses the light onto the other focus of the reflector. A baffle is located at the second focus to shape the focusing light to form the desired shape, and a projection lens is used to project the pattern far away from the headlamp. Actually, this is an effective way to form the light pattern as required in the ECE R112 regulation. However, the energy efficiency is low because the baffle blocks the unwanted part of the focusing light and loses energy. When a pcW-LED was applied to a low beam in 2008, the energy efficiency and the total flux were two issues. Thus, a clever method was proposed to use a beam shaper rather than a baffle to shape the light pattern, ${ }^{77}$ as shown in Fig. 10(b). The beam shaper is a high-reflective plate to adjust the reflection angle of the focusing beam on the plate. The plate is divided into two parts. One is to form the light pattern as required by the regulation, and the other is to redirect the light downward to enhance the luminous intensity of the light pattern. Such a design is effective not only for forming the required light pattern but also for saving energy. Figure 11 shows an alternative design that uses a light pipe to replace the elliptical reflector and the beam shaper. ${ }^{81,82}$ The light pipe is useful not only for mixing the light emitted by multiple pcW-LEDs but also for shaping the light pattern. Owing to the limited power of a single pcW-LED, there are several approaches to incorporating multiple pcW-LEDs in an optical modulator if more luminous flux is needed. A compound light pipe is proposed to combine several individual light pipes to incorporate multiple pcW-LEDs into a single exit face with a specific shape that is projected by an imaging lens to form the low beam pattern. ${ }^{78-80,83}$ Figure 12 shows a design to use multiple reflectors with a common focus to collect light emission from multiple pcW-LEDs. ${ }^{21,84}$ A simpler design is to use a tiny baffle in front of a pcW-LED to shape the low beam pattern without using an elliptical reflector, as shown in Fig. $13 .{ }^{85}$ However, such a simple approach is not energy efficient. An optics attached around the pcW-LED is necessary to adjust the divergent angle of the emission light to increase the energy efficiency.

The second type of optical design is a reflector that forms the low beam pattern. In comparison with the approach using a beam shaper with an imaging lens, a single reflector that is multisegment is more compact. However, forming a cutoff line is not straightforward. The beam
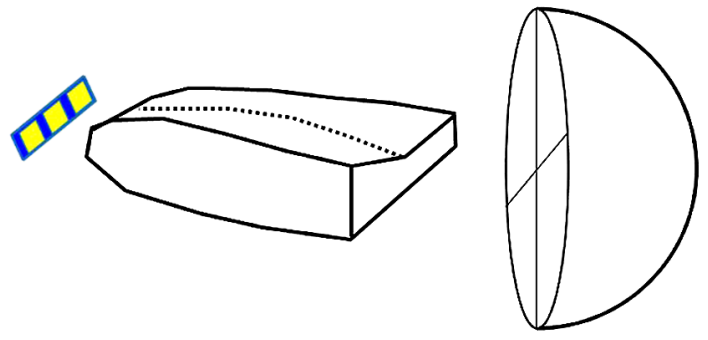

Fig. 11 A light guide is use to collect multiple pcW-LEDs and to shape the low beam pattern. ${ }^{78-80}$ 


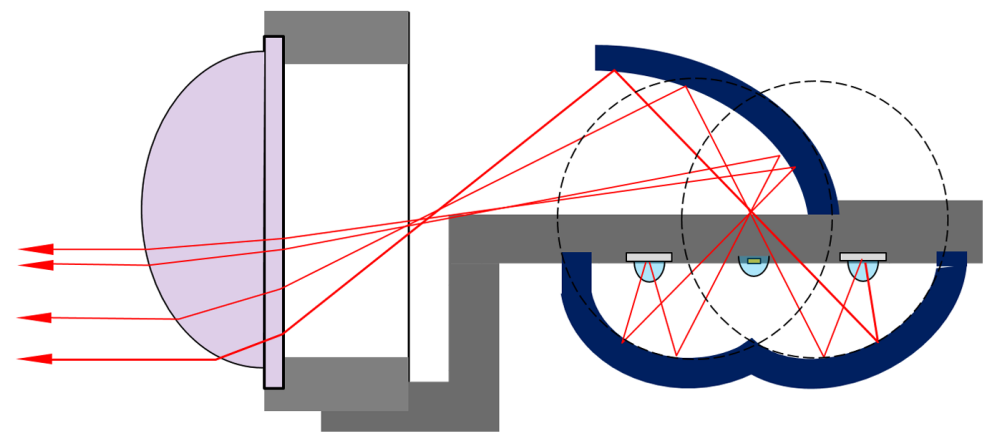

Fig. 12 Several elliptical reflectors are used to collect multiple pcW-LED reflectors. ${ }^{21,49}$

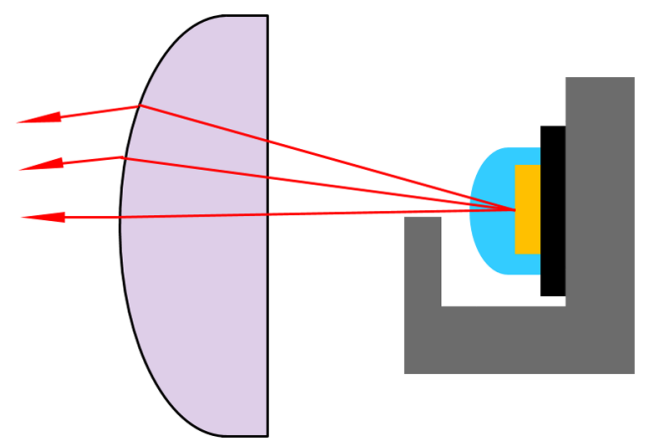

Fig. 13 Using a tiny baffle near the pcW-LED to shape the low beam pattern. ${ }^{85}$

(a)

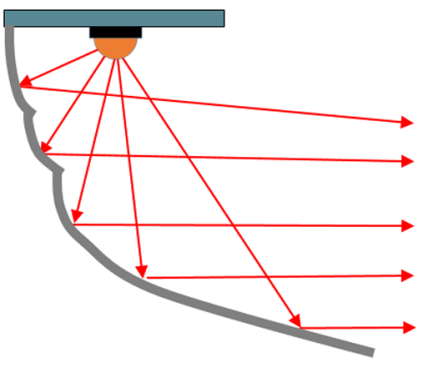

(b)

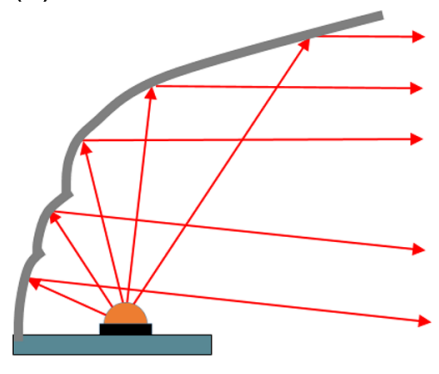

(c)

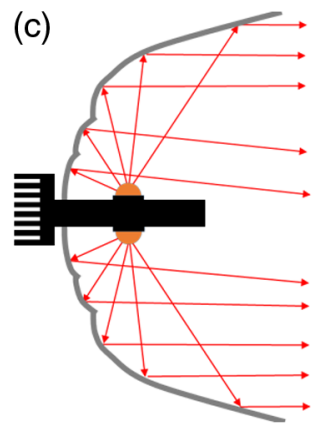

Fig. 14 The geometry structures of reflectors: (a) the downward type, (b) the upward type, and (c) a combination of these two types. ${ }^{86}$

shaping must be done through multiple segments with the technology called light field management. ${ }^{86,87}$ Figure 14 shows the most common geometries for a reflector. The pcWLED is placed on the top side or the bottom side of the reflector. A combination of these two types can be realized to take care of the low and high beams and to simplify the heat dissipation structure.

To design the reflector, light field management is necessary to effectively optimize the multiple segments. Light field management is a way to divide the light field by the pcW-LED with several segments, and the number of the segment is from 8 to 40 generally. For each segment, there are two factors that decide the role of the segment. The first is the etendue of the segment, and the second is the luminous flux. ${ }^{87}$ The segments having the smaller etendue are suitable for forming a high-contrast cutoff line. In contrast, the segments that bear larger luminous flux are suitable for providing the main illumination. In the headlamp of an automobile, the high-contrast cutoff line is formed by the reflected light from the segments with smaller etendue and higher luminous flux. Figure 15 shows an example of a multisegment reflector that forms the low beam with a pcW-LED and the high beam with the other pcW-LED. Owing to a single reflector with 
(a)

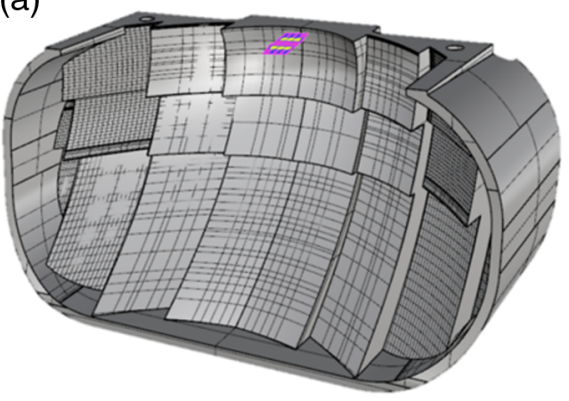

(b)

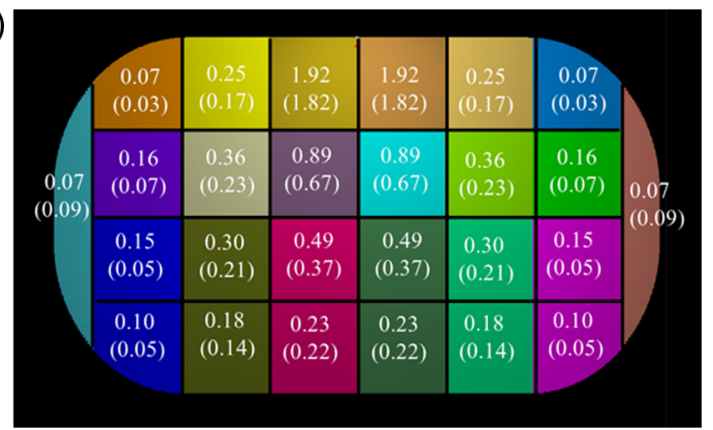

Fig. 15 An example of a multisegment reflector. (a) The geometry and (b) the 26 segments and the corresponding etendue and flux density in the unit of $1 \mathrm{~m} / \mathrm{mm}^{2} .{ }^{87}$

(a)

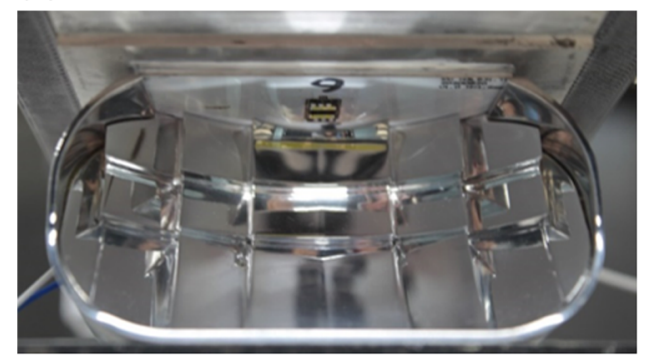

(b)

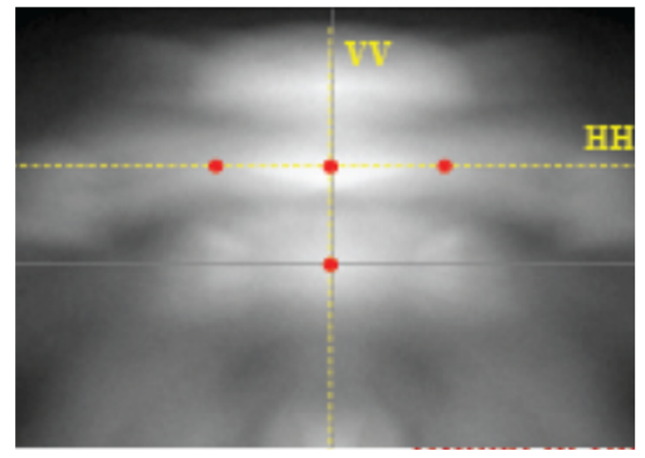

(c)

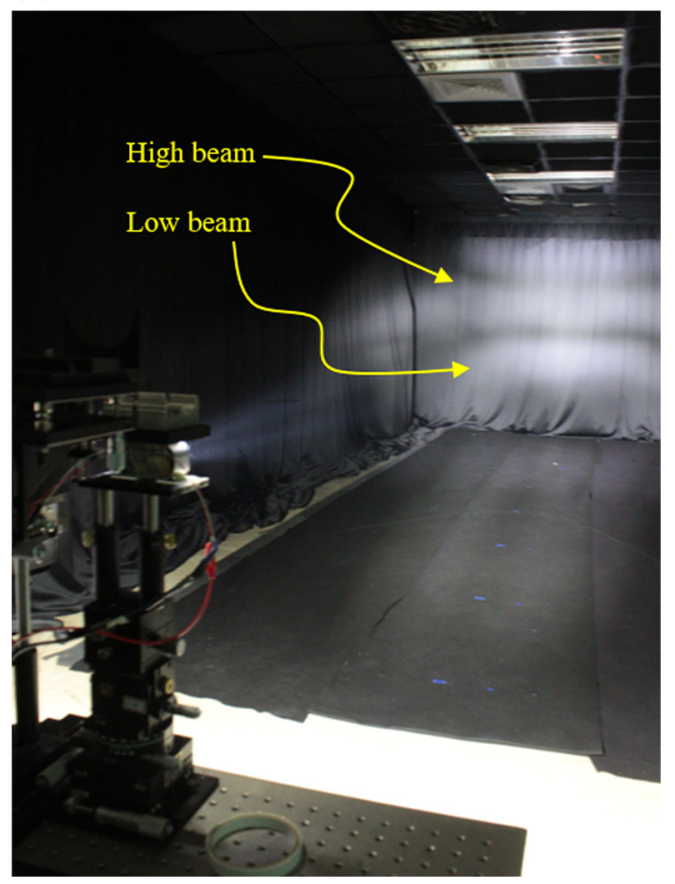

Fig. 16 (a) The prototype of the multisegment reflector, (b) the simulated light pattern at $10 \mathrm{~m}$, and (c) the experimental observation. ${ }^{87}$

two different light sources, each segment must play two roles for the two light sources. According to the light field management, the designer can calculate the etendue and the luminous exitance of each segment and choose the most appropriate segments to direct the light to form the low beam pattern. This means that the segments with the small etendue are used to form the cutoff line. The segments with middle etendue are used to form the major part of the high beam for the other pcW-LED. The segments with higher luminous exitance and higher etendue are not suitable for forming a tightened pattern, so they are tilted to redirect the incoming light to ground illumination. The simulated and observed light patterns are shown in Fig. $16 .{ }^{87}$

Multisegment reflectors have been successfully applied to various vehicle headlamps. For a bike or bicycle headlamp, a downward structure is preferred because it is helpful for the heat dissipation when the pcW-LED metal board that supports the pcW-LED is placed on the top of the headlamp. ${ }^{88}$ Figure 17 is an example of a $3 \mathrm{~W}$ pcW-LED serving as the light source; an eightsegment reflector is designed to form the light pattern for the K-mark regulation. The light field management technology is applied to the design, and the ground illumination is bright, uniform, and long enough to provide good vision to a rider. The situation of an automobile is different; 
(a)

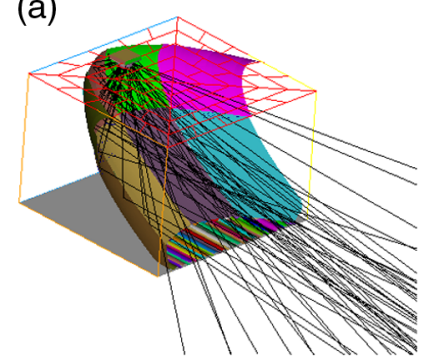

(b)

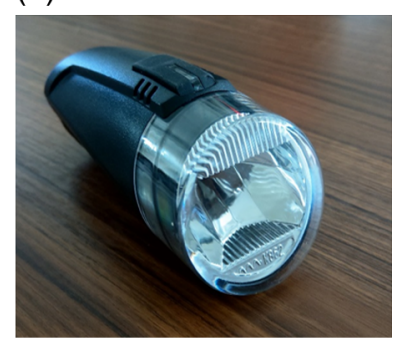

(c)

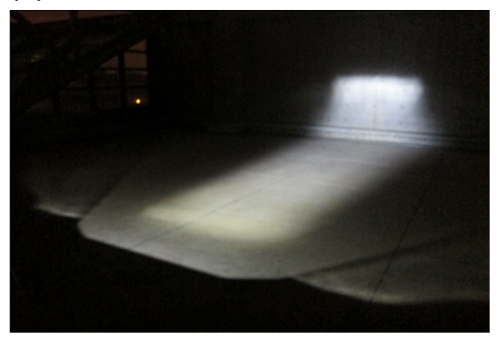

Fig. 17 (a) The structure of the reflector, (b) a photo of the bicycle headlamp, and (c) the projected light pattern. ${ }^{88}$

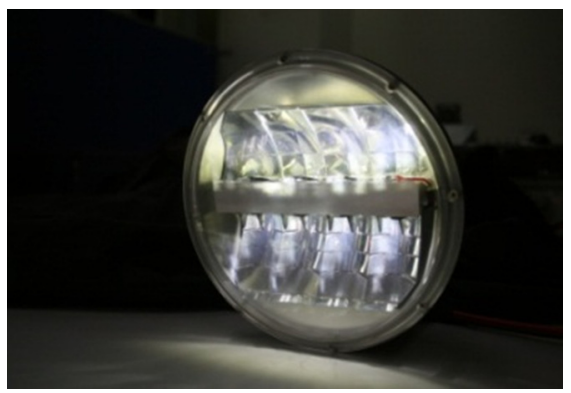

Fig. 18 A headlamp containing upward pcW-LEDs for the high beam and downward pcW-LEDs for the low beam.

there is more space for heat dissipation, so the downward and upward structures are not significant. Sometimes, a combination structure is more convenient for heat dissipation, as in the example shown in Fig. 18. The downward LED and the upward LED can be attached to the same metal board to save space.

Through good management of the light field and precise model of the pcW-LED, the design and simulation can well predict the light pattern on the target plane. For the application to a bicycle headlamp, a 1-W pcW-LED is shown to meet the minimum requirement of the K-mark regulation. ${ }^{27}$ To form a high-contrast cutoff line, there are various approaches related to using a reflector, including an L-shape light pipe and a truncated reflector with a cylindrical lens. ${ }^{23}$ In addition, using a cylindrical lens array on the exit face of a headlamp is helpful for increasing the contrast of the cutoff line and decreasing the manufacturing error. ${ }^{89,90}$

The third type of optical design is a complex lens or freeform lens that projects the desired light pattern. Typically, a complex lens contains a TIR structure to collimate the light by the pcWLED, and the structure on the exit face is used to adjust the projection light pattern. ${ }^{91}$ Figure 19 shows an example of a bicycle headlamp with a pcW-LED serving as the light source. The complex lens contains a TIR structure with three-segment exit faces. ${ }^{92}$ Each face forms a tightened

(a)

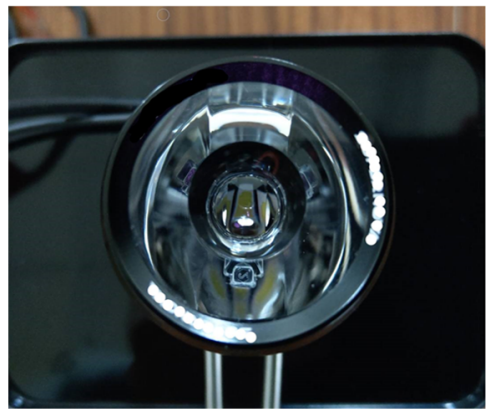

(b)

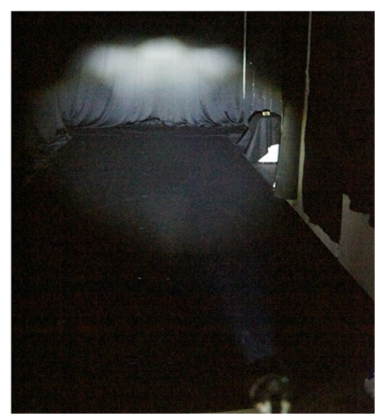

Fig. 19 (a) A bicycle headlamp containing a complex lens and (b) the projected light pattern. ${ }^{92}$ 


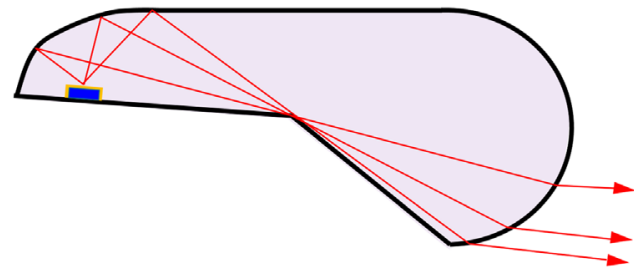

Fig. 20 An immerse freeform lens with full function to project the low beam pattern. ${ }^{93}$

spot on the target plane. The K-mark regulation does not require linearity of the cutoff line, but the bright zone of the light pattern must be laterally spread so that the light pattern meets the regulation.

Another kind of complex lens is the freeform lens, in which the surface of the lens is designed to shape the projection light pattern. Based on the ray function of the light source and the regulation, the freeform surface is designed to reach the target. Figure 20 shows an example of a clever design that combines an elliptical reflector, a beam shaper, and a projection lens into a single volume. ${ }^{93}$ However, the design of the immersed pcW-LED could encounter problems in manufacturing and heat dissipation. In addition, the volume of the lens is another problem in manufacturing because shrinkage through plastic injection molding is unavoidable. Therefore, keeping the accuracy of the lens shape is a challenge for the manufacturer. To this point, the multisegment reflector is more robust and common than a complex lens in vehicle headlamps.

A successful optical design pays attention not only to the design and simulation but also to the manufacturing quality. The complex lenses could suffer from shrinkage of the lens volume during the molding process. The multisegment reflector could suffer from deformation during the injection molding process of the plastic reflector. In a multisegment reflector, more segments mean more boundaries between every two segments. The stress on the boundary induced through the molding process could induce nonneglectful deformation and cause stray light across the dark region. This effect could reduce the contrast of the cutoff line of the low beam and falls to meet the regulation. Precise thermal analysis of the injection molding process could simulate the shrinkage of the reflector. ${ }^{94}$ Once the stray light affects the contrast, a profile meter is used to detect the surface of the reflector and check if there is serious deformation of the reflector. Figure 21 shows an example of this issue. An eight-segment reflector was designed to meet the K-mark regulation. In the design and simulation, the contrast reaches 9600 , which is the ratio of the illuminance at point $\mathrm{A}$ and the highest illuminance in the dark zone, as shown in Fig. 22. However, the illumination by the prototype performs a different behavior. The illuminance at point A reduces to 118 lux in comparison with 123.6 lux in the simulation. But the illuminance at point $\mathrm{HV}$ in the dark region reaches 7.9 lux in comparison with 0.01 lux in the simulation. The profile scanner is used to reconstruct the surface profile of the reflector. Through the simulation based on the scanned profile, the light pattern and the illuminance at the important checkpoints show similar illumination behavior with the measurement. The surface deformation becomes one of the key factors to watch the manufacturing quality and the design capability as well.
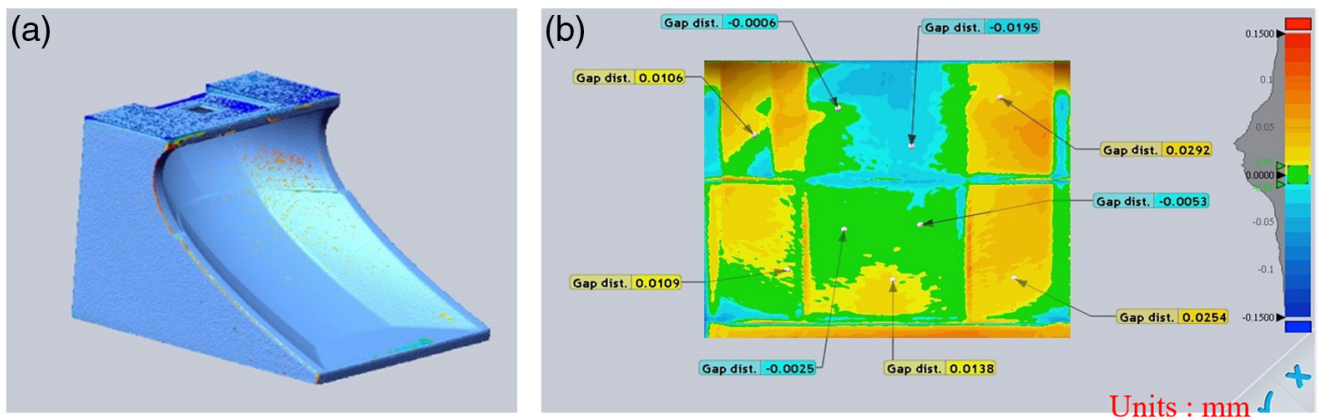

Fig. 21 (a) The geometry of the eight-segment reflector and (b) the profile scanning result for the surface, where the part in green closely fits the design. 
(a)

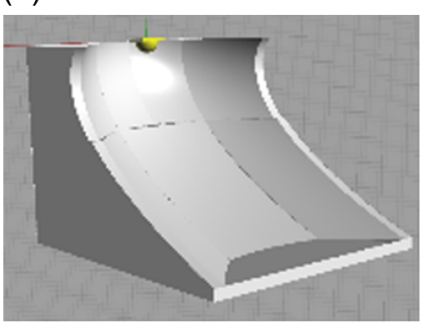

(b)

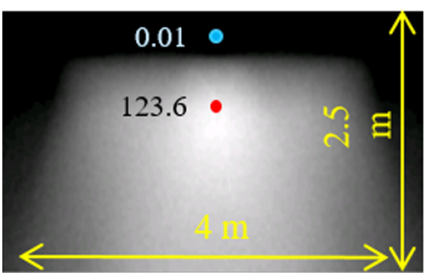

(c)

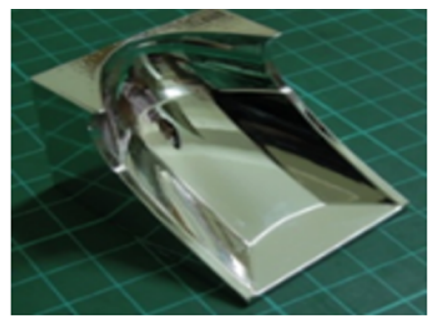

(d)

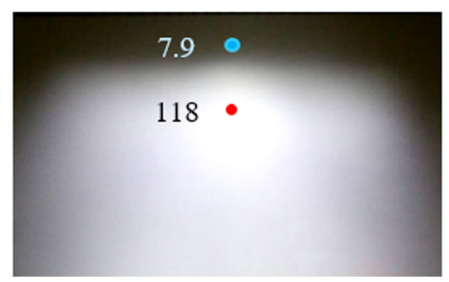

(e)

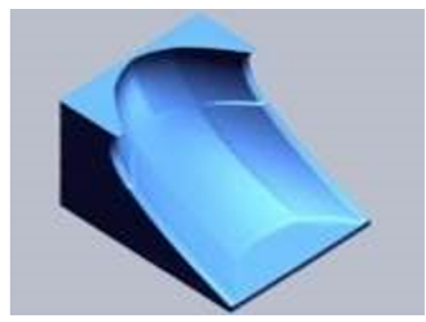

(f)

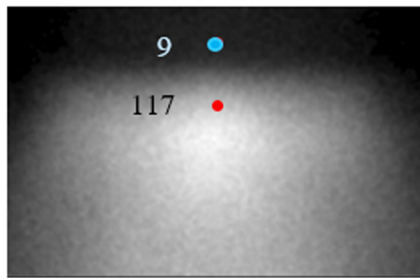

Fig. 22 (a) The designed reflector, (b) the simulated light pattern at $10 \mathrm{~m}$, (c) the prototype, (d) the experimental measurement, (e) the reconstructed reflector, and (f) the simulation result based on (e). The numbers indicate the illuminance at the check point of HV (the blue spot) and A (the red spot).

\section{Adaptive Headlamps}

The major illumination of the forward lighting is by the low beam or the high beam of a vehicle. A high beam can provide clear vision to a driver or a rider, but it could induce glare to people on the roadway. Thus, the low beam is the necessary forward lighting for a vehicle without causing glare. If there is a way to extend the illumination area according to the driving circumstance but not to cause glare, the driver's vision will be greatly improved. The adaptive headlamps are made for this purpose. ${ }^{95-101}$ Figure 23 shows an example of a feature of an adaptive headlamp. ${ }^{102}$ The automobile equipped with the adaptive headlamp can automatically switch between the low beam and high beam. But in most conditions, the extension beam is the typical mode that provides clearer vision. When there is an oncoming car or a car is in front of the automobile, the adaptive headlamp dims the parts of the light pattern causing glare to people or switches to the

(a)

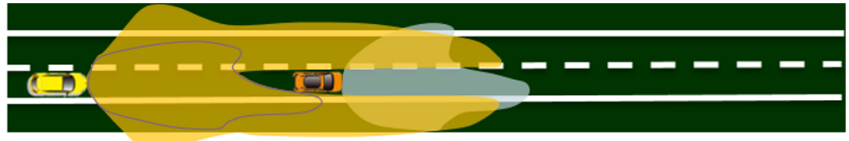

(b)

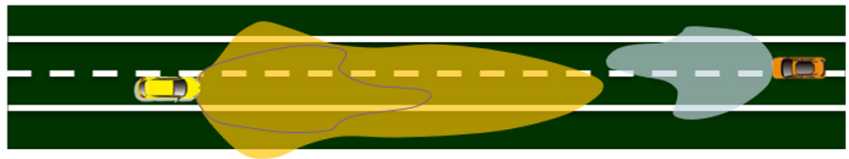

(c)

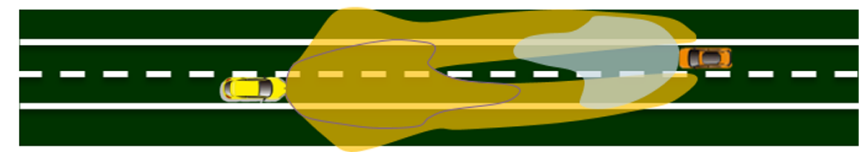

(d)

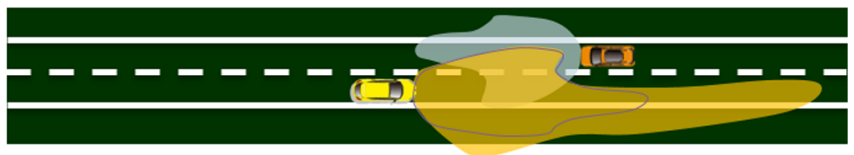

Fig. 23 A conceptual demo of the application of an adaptive headlamp. (a) The high beam with a dimming part when following a car, (b) the pure high beam, (c) the high beam with a dimming part when facing an oncoming car, and (d) a mixture of high beam and low beam when the oncoming car is near. ${ }^{102}$ 
mode with a mix of the low beam and the high beam patterns. The adaptive headlamp is a breakthrough technology in forward lighting owing to high-speed image sensing and local-dimming illumination technology.

The local-dimming forward lighting can be done through several approaches. The first is to replace a pcW-LED with a laser diode (LD). A blue LD is similar to a blue LED in many aspects; it can be used to pump a yellow phosphor for downconversion and finally appears as a white light source, ${ }^{103-110}$ as shown in Fig. 24, where the phosphor is excited by blue light from an LD. If a blue laser light is two-dimensional (2-D) scanned on a yellow phosphor, a lens can be used to project the light pattern far away from the vehicle to form the forward lighting. The light pattern could be adaptive when the laser light is modulated according to the image sensing on the roadway. The advantage of using laser scanning on a phosphor is that the dimming part can be quickly adjusted, as shown in Fig. 25. But the mechanical part of the 2-D scanner must be robust in a dynamic circumstance by a driving automobile.

To avoid using a vibrating component, one of the approaches is to build up a light source with a pcW-LED matrix. ${ }^{111}$ Through an imaging lens, the shape of the bright zone using the matrix is

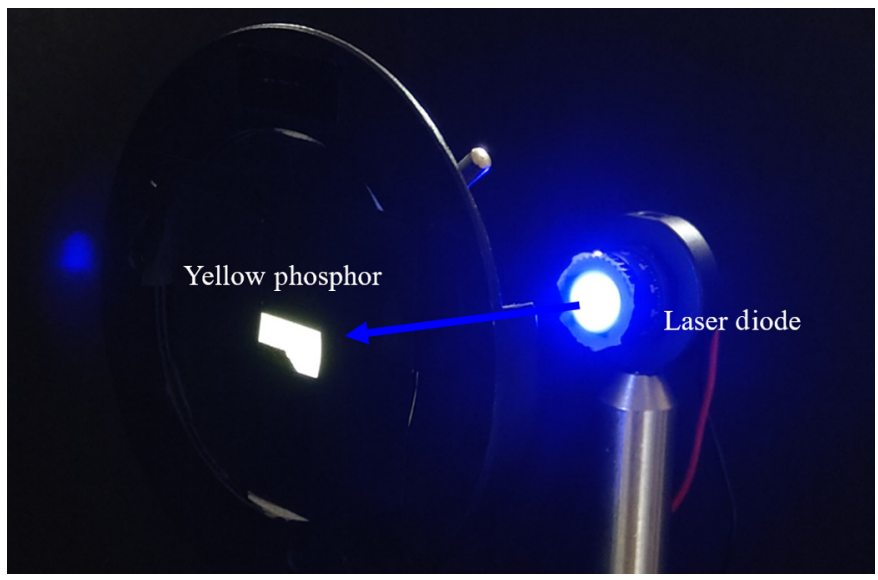

Fig. 24 A yellow phosphor is illuminated by a blue LD and appears as a white light source with a specific shape.

(a)

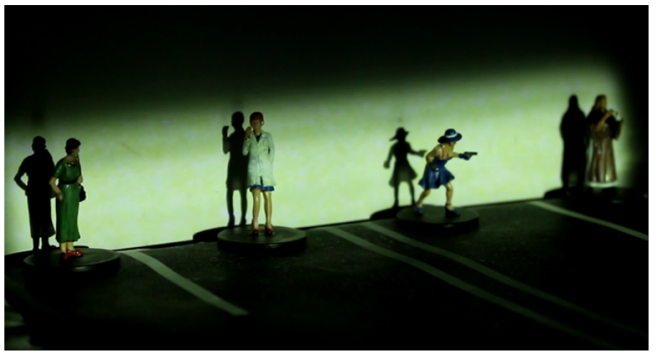

(c)

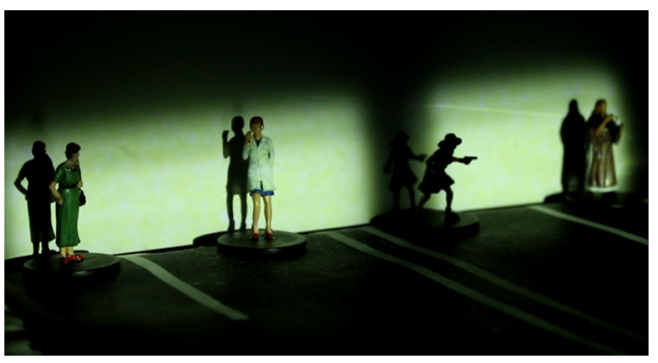

(b)

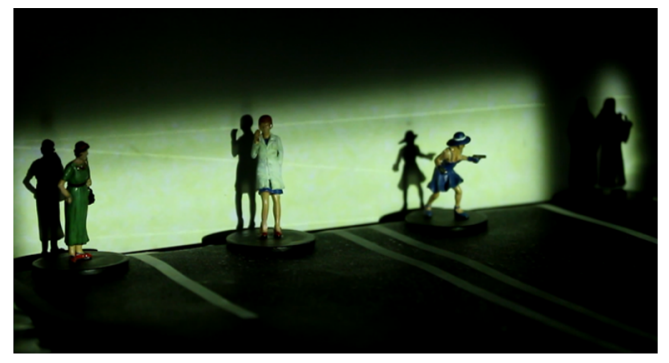

(d)

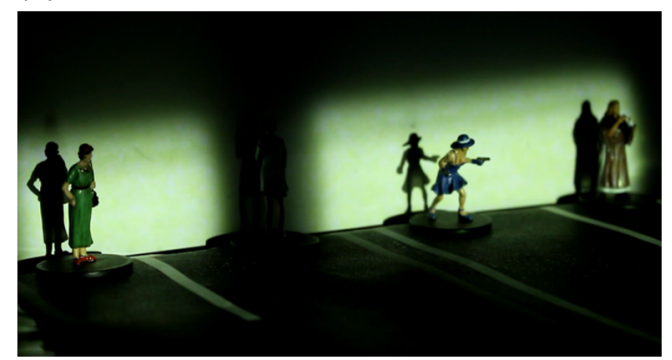

Fig. 25 (a) The complete light pattern, (b) a dimming part on the right side, (c) on the central right side, and (d) on the central left side. 


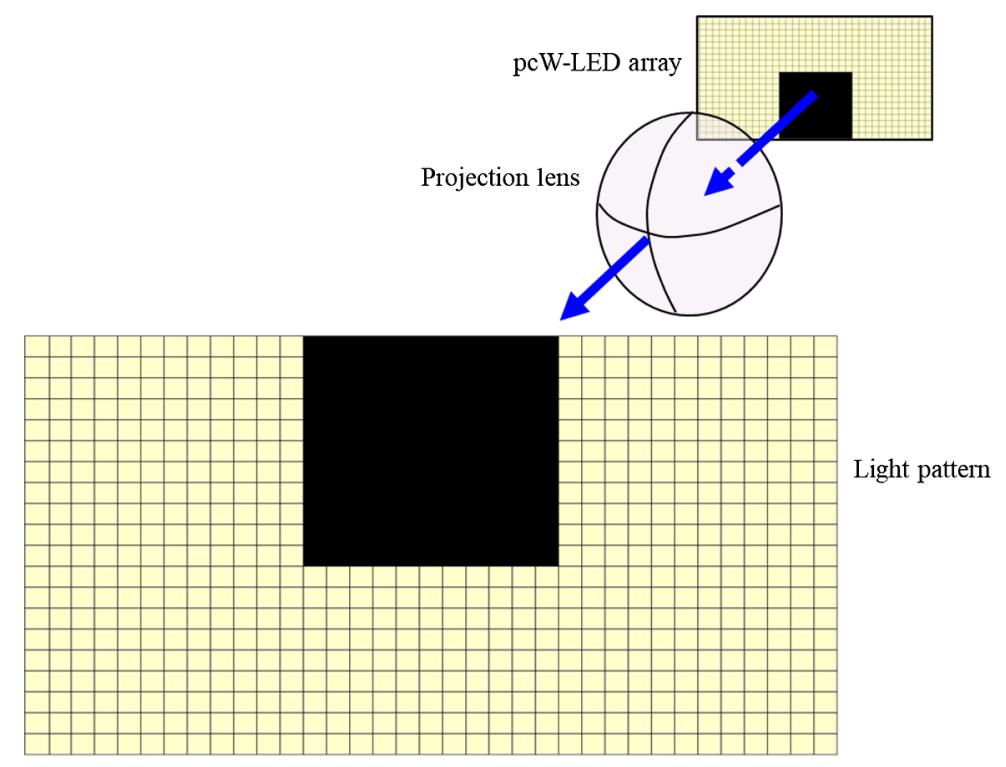

Fig. 26 A schematic diagram of the adaptive headlamp with use of a pcW-LED array. The black part corresponds to the off-state parts of the pcW-LED.

projected to the roadway. As shown in Fig. 26, the dimming part of the light pattern on the roadway corresponds to the pcW-LEDs in the turn-off mode on the matrix. To have a highquality light pattern, the pixel number of the pcW-LED matrix (also called the lighting panel) must be carefully calculated so the spatial resolution of the dimming shape is high enough.

When the pixel number of the lighting panel is increased to a certain level and the projection lens is kept to an acceptable size, the pcW-LED should be small. If the dimensions of the lighting panel are set to $5 \mathrm{~mm} \times 10 \mathrm{~mm}$ and a total of 800 to 5000 active pixels are contained, the LED size should be around 100 to $250 \mu \mathrm{m}$, which is in the range of the mini LED. ${ }^{112}$ An alternative way to provide a high-density dimming light pattern is to use a spatial light modulator. ${ }^{113}$ The digital micromirror device by Texas Instruments that contains millions of vibration mirrors is an effective panel to form a dynamic light pattern through optical projection. ${ }^{114}$ The design of the projection system is similar to that in the video projector, ${ }^{115}$ but the objective is illumination rather than display, so the luminous intensity across the light pattern must meet the regulation. Here, the beam intensity profile is one key factor in building up the light source.

\section{Summary}

We reviewed the current optical design approaches for vehicle forward lighting based on solidstate lighting. The vehicles including bicycles, bikes, and automobiles. The headlamps include the low beam and high beam. The low beam is regarded as the most important headlamp because of the balance between illumination and antiglare. Then, we introduced several important regulations for various kinds of vehicles. For the requirement of the low beam, a cutoff line is necessary. The contrast of the cutoff line depends on the vehicle speed in the regulation. Even for a bicycle headlamp, the cutoff line is not easily achieved because the headlamp is always required to be light, compact, low power, and low cost.

In the optical design, we introduced three kinds of approaches. The first is a projection lens with a baffle and a focusing mirror. An improved approach was proposed by replacing a traditional baffle with a beam shaper, so the luminous flux by the light sources can be utilized in higher efficiency. The second is the multisegment reflector. Incorporated with light field management technology and a precise light source model, a multisegment reflector could redirect the coming light to the target plane and form a light pattern as required. Light field management technology is a way to analyze the etendue and the flux density of the illumination on each segment by the light source and then to decide the role of each segment. Through the technology, a single reflector can 
project low beam and high beam patterns at the same time and meet various regulations. The third is the complex lens that includes a freeform lens. A complex lens utilizes most boundaries of the lens to redirect the light from the light source to the target plane. However, owing to the limit in the lens volume, the usage of a complex lens is not as common as a multisegment reflector.

In the final section of this review, we introduce the goal and the advantages of an adaptive headlamp, which can provide a driver with brighter and clearer vision while avoiding causing glare to people on the roadway. The technology to support the adaptive headlamps are highspeed image sensing technology, signal processing technology, and local-dimming illumination technology. The optical approaches including laser scanning, a high-density pcW-LED matrix, and utilization of a spatial light modulator to provide a variable light pattern, which is similar to the design of a video projector, but the light source design should provide an appropriate light profile and the power management of the light source should be well designed.

\section{Acknowledgments}

The authors thank the Ministry of Science and Technology of Taiwan with Grant Nos. of MOST 108-2622-E-008-010-CC2 and 109-2622-E-008-014-CC2.

\section{References}

1. P. Schlotter, R. Schmidt, and J. Schneider, "Luminescence conversion of blue light emitting diodes," Appl. Phys. A 64, 417-418 (1997).

2. S. Nakamura, S. Pearton, and G. Fasol, The Blue Laser Diode: The Complete Story, Springer-Verlag (2000).

3. N. Narendran et al., "Characterizing white LEDs for general illumination applications," Proc. SPIE 3938, 240-248 (2000).

4. A. Zukauskas, M. S. Shur, and R. Caska, Introduction to Solid-State Lighting, John Wiley \& Sons, New York (2002).

5. D. A. Steigerwald et al., "Illumination with solid state lighting technology," IEEE J. Sel. Top. Quantum Electron. 8, 310-320 (2002).

6. E. F. Schubert and J. K. Kim, "Solid-state light sources becoming smart," Science 308, 1274-1278 (2005).

7. L. Venema, "The art of illumination," Nature 450, 1175 (2007).

8. S. Pimputkar et al., "Prospects for LED lighting," Nat. Photonics 3, 180 (2009).

9. C. C. Sun et al., "Packaging efficiency in phosphor-converted white LEDs and its impact to the limit of luminous efficacy," J. Solid State Light. 1, 19 (2014).

10. R. Karlicek et al., Handbook of Advanced Lighting Technology, Springer, Cham, Switzerland (2017).

11. "Traffic safety facts 2000: a compilation of motor vehicle crash data from the fatality analysis reporting system and the general estimate system," in US Department of Transportation, NHTSA National Highway Traffic Safety Administration (2001).

12. J. Sullivan and M. Flannagan, "Assessing the potential benefit of adaptive headlighting using crash databases," University of Michigan Transportation Research Institute, Report UMTRI-99-21 (1999).

13. M. Hamm, "Adaptive lighting functions history and future: performance investigations and field test for user's acceptance," SAE Technical Paper 2002-01-0526 (2002).

14. "Nichia breaks $100 \mathrm{~lm} / \mathrm{W}$ barrier for a white LED," 2006, https://www.ledsmagazine.com/ architectural-lighting/indoor-lighting/article/16699406/nichia-breaks-100-lmw-barrier-fora-white-led.

15. P. Brick and T. Schmid, "Automotive headlamp concepts with low-beam and high-beam out of a single LED," Proc. SPIE 8170, 817008 (2011).

16. L. G. Novakovsky, "Train illumination is a key problem of forming underground light medium," Light Eng. 19, 10-25 (2011).

17. W. L. Liang and G. D. J. Su, "Design of a high-efficiency train headlamp with low power consumption using dual half-parabolic aluminized reflectors," Appl. Opt. 57, 1305-1314 (2018). 
18. LumiLeds, “Lumileds' Luxeon LEDs illuminate headlamps in concept car,” 2002, https:// www.theautochannel.com/news/2002/03/05/036708.html.

19. Mitsubishi Motors, "SSU," 2002, http://www.mitsucars/company/road_ahead/concept_ cars.html.

20. J. F. V. Derlofske and M. McClogan, "White LED sources for vehicle forward lighting," Proc. SPIE 4776, 195-205 (2002).

21. W. S. Sun et al., "Optical design of an LED motorcycle headlamp with compound reflectors and a toric lens," Appl. Opt. 54, E102-E108 (2015).

22. X. F. Li et al., "A light-emitting diode headlamp for motorcycles based on freeform microlenses," Lighting Res. Technol. 47, 495-506 (2015).

23. Y. C. Lo et al., "Design of a bike headlamp based on a power white-LED," Opt. Eng. 50, 080503 (2011).

24. "ECE," http://www.unece.org/trans/main/wp29/wp29regs101-120.html.

25. "Magneti Marelli automotive lighting launches new LED module production in NAFTA," 2016, http://www.magnetimarelli.com/press_room/news/magneti-marelli-automotivelighting-launches-new-led-module-production-nafta.

26. "ISO 6742-1:2015 - Estonian Centre for Standardisation," 2015, https://www.evs.ee/ products/iso-6742-1-2015.

27. H. J. Lin et al., "Design of K-mark bike headlamp using white LED with separate die bonding," Crystals 9, 659 (2019).

28. W. T. Chien, C. C. Sun, and I. Moreno, "Precise optical model of multi-chip white LEDs," Opt. Express 15, 7572-7577 (2007).

29. R. J. Koshel, Illumination Engineering: Design with Nonimaging Optics, Wiley, Hoboken, New Jersey (2013).

30. H. Rehn and J. Muschaweck, "Étendue estimation for non-trivial geometry," in $\mathrm{DGaO}$ Proc. (2020).

31. R. Winston, J. C. Miñano, and P. Benítez, Nonimaging Optics, Elsevier Academic Press, Burlington, Massachusetts (2005).

32. J. Chaves, Introduction to Nonimaging Optics, 2nd ed., CRC Press, Boca Raton, London (2016).

33. A. V. Arecchi, T. Messadi, and R. J. Koshel, Field Guide to Illumination, SPIE Press, Bellingham, Washington (2007).

34. G. Brooker, Modern Classical Optics, Oxford University Press, New York (2003).

35. V. N. Mahajan, Optical Imaging and Aberrations, SPIE Press, Bellingham, Washington (1998).

36. OSRAM GmbH, https://www.osram.com/cb/.

37. Cree Inc., https://cree-led.com/.

38. C. C. Sun et al., "Precise optical modeling for LED lighting based on cross-correlation in mid-field region," Opt. Lett. 31, 2193-2195 (2006).

39. C. C. Sun et al., "Precise optical modeling for silicate-based white LEDs," Opt. Express 16, 20060-20066 (2008).

40. C. C. Hung et al., "Optical design of automotive headlight system incorporating digital micro mirror device," Appl. Opt. 49, 4182-4187 (2010).

41. M. S. Huang et al., "Optical design and optimization of light emitting diode automotive head light with digital micro mirror device light emitting diode," Optik 121, 944-952 (2010).

42. Y. C. Lo et al., "A compact bike head lamp design based on a white LED operated at one watt," Opt. Laser Technol. 44, 1172-1175 (2012).

43. A. Ge et al., "Design of an LED-based compound optical system for a driving beam system," Appl. Opt. 52, 2688-2693 (2013).

44. P. Qiu et al., "Design of an LED-based headlamp low-beam system using combined prisms," Lighting Res. Technol. 47, 248-253 (2015).

45. C. S. Wu et al., "Design of LED spot light system with projection distance reaching 10 km," Crystals 9, 524 (2019).

46. J. C. Minano et al., "High efficiency non-imaging optics," United States Patent, US6639733B2 (2003). 
47. J. Chen, K. Huang, and P. Lin, "Computer modeling of a fiber and-light-emitting-diodebased vehicle headlamp," Opt. Eng. 49, 073002 (2010).

48. A. M. Ge et al., "High-energy-efficiency optical system for an LED-based headlamp architecture," Appl. Opt. 52, 8318 (2013).

49. S. C. Chu et al., "Design of a high-efficiency LED low-beam headlamp using Oliker's compound ellipsoidal reflector," Appl. Opt. 59, 4872-4879 (2020).

50. J. H. Lee, S. G. Han, and M. J. Jin, "Minimum achievable height of a single-module LED low-beam projection headlamp," Appl. Opt. 60, E8-E16 (2021).

51. V. I. Oliker and O. von Tempski, "On the design of reflectors with prespecified distribution of virtual sources and intensities," Inverse Prob. 14, 661-678 (1998).

52. P. Benítez, R. Mohedano, and J. C. Miñano, "Design in 3D geometry with the simultaneous multiple surface design method of nonimaging optics," Proc. SPIE 3781, 12-21 (1999).

53. W. Yan and W. Mao, "A multi-reflector headlamp that can produce a diagonal cut-off without a shield," Proc. Inst. Mech. Eng. 214, 839-842 (2000).

54. J. H. Park and J. Y. Sah, "Design of reflector optics with smooth surface for automotive lamps," SAE Tech. Pap. 2001-01-0457 (2001).

55. P. Benítez and J. C. Miñano, "Simultaneous multiple surface optical design method in three dimensions," Opt. Eng. 43, 1489-1502 (2004).

56. H. J. Park et al., "Design of LED bicycle headlamp with a horizontally wide viewing angle," Curr. Opt. Photonics 1, 351-357 (2017).

57. H. Ries and J. A. Muschaweck, "Tailoring freeform lenses for illuminations," Proc. SPIE 4442, 43-50 (2001).

58. O. Dross et al., "LED headlight architecture that creates a high quality beam pattern independent of LED shortcomings," Proc. SPIE 5942, 59420D (2005).

59. P. Benitez et al., "Three-dimensional simultaneous multiple-surface method and freeform illumination-optics designed therefrom," United States Patent, US7460985B2 (2004).

60. L. Wang, K. Qian, and Y. Luo, "Discontinuous free-form lens design for prescribed irradiance," Appl. Opt. 46, 3716-3723 (2007).

61. Y. Ding et al., "Freeform LED lens for uniform illumination," Opt. Express 16, 1295812966 (2008).

62. L. Sun, S. Jin, and S. Cen, "Free-form microlens for illumination applications," Appl. Opt. 48, 5520-5527 (2009).

63. Z. R. Zheng, X. Hao, and X. Liu, "Freeform surface lens for LED uniform illumination," Appl. Opt. 48, 6627-6634 (2009).

64. F. Chen et al., "Design method of high-efficient LED headlamp lens," Opt. Express 18, 20926-20938 (2010).

65. Y. Luo et al., "Design of compact and smooth free-form optical system with uniform illuminance for LED source," Opt. Express 18(9), 9055-9063 (2010).

66. R. Wu et al., "Free-form lens arrays for off-axis illumination in an optical lithography system," Appl. Opt. 50, 725-732 (2011).

67. X. B. Zhu et al., "Optical design of LED-based automotive headlamps," Opt. Laser Technol. 45, 262-266 (2013).

68. E. Aslanov, L. L. Doskolovich, and M. A. Moiseev, "Thin LED collimator with free-form lens array for illumination applications," Appl. Opt. 51, 7200-7205 (2012).

69. J. J. Chen et al., "Freeform lens design for LED collimating illumination," Opt. Express 20, 10984-10995 (2012).

70. C. C. Hsieh, Y. H. Li, and C. C. Hung, "Modular design of the LED vehicle projector headlamp system," Appl. Opt. 52, 5221-5229 (2013).

71. X. H. Lee, I. Moreno, and C. C. Sun, "High-performance LED street lighting using microlens arrays," Opt. Express 21, 10612-10621 (2013).

72. P. Ge et al., "LED high-beam headlamp based on free-form microlenses," Appl. Opt. 53, 5570-5575 (2014).

73. E. Chen, R. Wu, and T. Guo, "Design a freeform microlens array module for any arbitrary-shape collimated beam shaping and color mixing," Opt. Commun. 321, 78-85 (2014). 
74. Y. C. Lo et al., "Side-illuminating LED luminaires with accurate projection in high uniformity and high optical utilization factor for large-area field illumination," Opt. Express 22, A365-A375 (2014).

75. C. C. Sun et al., "Design of LED street lighting adapted for free-form roads," IEEE Photonics J. 9, 8200213 (2017).

76. S. Fujiyoshi and T. Nakagawa, "Lighting apparatus for vehicle and method of controlling a headlamp," Japan Patent, JP5941800B2 (2016).

77. Y. Nakada and Y. Ugajin, "Vehicular headlamp," United States Patent, US9222638B2 (2015).

78. M. Wanninger and A. Wilm, "Lighting means having a predetermined emission characteristic, and a primary optics element for a lighting means," United States Patent, US20060083013A1 (2006).

79. T. Tessnow, R. Johnson, and M. Tucker, "Application of LED light sources with light guide optics," SAE Tech. Pap.2007-01-1041 (2007).

80. T. Tessnow and R. Johnson, "LED headlamp system," United States Patent, US20090034278A1 (2009).

81. A. J. W. Whang et al., "An innovative vehicle headlamp design based on high-efficiency LED light pipe system," Lighting Res. Technol. 47, 210-220 (2015).

82. H. C. Chen et al., "Investigation of structure in the modular light pipe component for LED automotive lamp," Proc. SPIE 9190, 919010 (2014).

83. A. Cvetkovic et al., "Etendue-preserving mixing and projection optics for high-luminance LEDs, applied to automotive headlamps," Opt. Express 14, 13014-13020 (2006).

84. H. Chen, J. Zhou, and Y. Zhou, "Stacking illumination of a confocal reflector light emitting diode automobile headlamp with an asymmetric triangular prism," Appl. Opt. 56, 1087-1093 (2017).

85. M. Tatsukawa et al., "Vehicular headlamp," United States Patent, US7128453B2 (2003).

86. C. C. Sun et al., "Anti-glare LED projection lamp based on an optical design with a confocal double-reflector," Opt. Commun. 285, 4207-4210 (2012).

87. C. C. Sun et al., "Single reflector design for integrated low/high beam meeting multiple regulations with light field management," Opt. Express 29, 18865-18875 (2021).

88. J. Y. Cai et al., "Design of a highly efficient LED-based bicycle head lamp with additional ground illumination," Light. Res. Technol. 46, 747-753 (2014).

89. M. Weber et al., "Giant birefringent optics in multilayer polymer mirrors," Science 287, 2451-2456 (2000).

90. M. S. Tsai et al., "Robust optical design for high-contrast cut-off line in vehicle forward lighting," OSA Continuum 2, 1080-1088 (2019).

91. H. Wang et al., "Design of a newly projected light-emitting diode low-beam headlamp based on microlenses," Appl. Opt. 54, 1794-1801 (2015).

92. Supernova, https://supernova-lights.com/en/.

93. H. Ishida and S. Ken, "Vehicular headlamp and optical unit," United States Patent, US7073931B2 (2006).

94. S. H. Tang et al., "Design and thermal analysis of plastic injection mould," J. Mater. Process. Technol. 171, 259-267 (2006).

95. United Nations Economic Commission for Europe (UNECE), "Uniform provisions concerning the approval of adaptive front-lighting systems (AFS) for motor vehicles," ECE324-R123 (2013).

96. J. H. Lee et al., "Automotive adaptive front lighting requiring only on/off modulation of multi-array LEDs," Curr. Opt. Photonics 1, 207-213 (2017).

97. H. Yu et al., "Smart headlamp optics design and analysis with multi- array LEDs," Korean J. Opt. Photonics 24, 231-236 (2013).

98. P. Dubal and J. D. Nanaware, "Design of adaptive headlights for automobiles," Int. J. Recent Innovation Trends Comput. Commun. 3, 1599-1603 (2015).

99. Hella Corporation, http://www.hella.com/.

100. Y. C. Liou and W. L. Wang, "Lighting design of headlamp for adaptive front-lighting system," J. Chin. Inst. Eng. 30, 411-422 (2007). 
101. R. Ma, "Automotive adaptive front-lighting system reference design," Texas Instruments (2013).

102. "BMW adaptive LED headlights functionality," https:/www.youtube.com/watch?v= 8Y3tkMD6Vew.

103. C. Basu, M. Meinhardt-Wollweber, and B. Roth, "Lighting with laser diodes," Adv. Opt. Technol. 2, 313-321 (2013).

104. J. J. Wierer, J. Y. Tsao, and D. S. Sizov, "Comparison between blue lasers and light-emitting diodes for future solid-state lighting," Laser Photonics Rev. 7, 963-993 (2013).

105. L. Ulrich, "Whiter brights with lasers," IEEE Spectr. 50, 36-56 (2013).

106. K. A. Denault et al., "Efficient and stable laser-driven white lighting," AIP Adv. 3, 072107 (2013).

107. M. Cantore et al., "High luminous flux from single crystal phosphor-converted laser-based white lighting system," Opt. Express 24, A215-A221 (2016).

108. Y. Yang, S. Zhuang, and B. Kai, "High brightness laser-driven white emitter for Etenduelimited applications," Appl. Opt. 56, 8321-8325 (2017).

109. C. Wu et al., "Phosphor-converted laser-diode-based white lighting module with high luminous flux and color rendering index," Opt. Express 28, 19085-19096 (2020).

110. S. Y. Tu, H. Y. Lin, and T. X. Lee, "Efficient speckle-suppressed white light source by micro-vibrated and color-mixing techniques for lighting applications," Opt. Express 23, 26754-26768 (2021).

111. I. Moreno, "Image-like illumination with LED arrays: design," Opt. Lett. 37, 839-841 (2012).

112. G. Tan et al., "High dynamic range liquid crystal displays with a mini-LED backlight," Opt. Express 26, 16572-16584 (2018).

113. J. Goodman, Introduction to Fourier Optics, 2nd ed., McGraw-Hill, New York (1996).

114. J. B. Caldwell, "Wide-angle DMD projection lens," Opt. Photonics News 10, 51-52 (1999).

115. J. W. Pan and S. H. Lin, "Achromatic design in the illumination system for a mini projector with LED light source," Opt. Express 19, 15750-15759 (2011).

Ching-Cherng Sun received his PhD from the National Central University in 1993. He has been a chair professor since 2014 at NCU. He was presented four national awards in 2009 to 2015 and the engineering award of TPS. He is currently a fellow of SPIE and OSA and the president of TPS. He has authored and coauthored more than 160 refereed papers. His major research includes holography, LED solid-state lighting, optical design, and MR near-eye technology.

Chi-Shou Wu is a PhD student of Department of Optics and Photonics at the National Central University. He received his MS degree in applied physics from Chung Yuan Christian University in 2002. His current research interests include solid-state lighting and optical design.

Yong-Sheng Lin is a master's student in the Department of Optics and Photonics at the National Central University. He received his bachelor's degree in the Department of Photonics from Feng Chia University in 2020. His current research interests include solid-state lighting and optical design.

Yi-Jou Lin is an MS student in the Department of Optics and Photonics at the National Central University. She received her bachelor's degree in the Graduate Department of Opto-Electronic Engineering from the National Dong Hwa University in 2019. Her current research interests include solid-state lighting and optical design.

Cheng-Yan Hsieh is an MsD student in the Department of Optics and Photonics at the National Central University. He received his MS degree in 2021. His research interests are solid-state lighting and optical design.

Shih-Kang Lin is a PhD student in the Department of Optics and Photonics at the National Central University. He received his MS degree in the Graduate Institute of Photonics from the 
National Changhua University of Education in 2016. His current research interests include solidstate lighting and optical design.

Tsung-Hsun Yang received his BS degrees in electro-physics and in applied mathematics from the National Chiao Tung University in 1988 and his $\mathrm{PhD}$ in electro-optical engineering, from the National Chiao Tung University in 1998. He is currently a professor in the Department of Optics and Photonics at the National Central University. His research interests are color management for LED lighting and display, precision colorimetry, micro-optics, optical MEMS for biosensors, and nonlinear chaotic dynamics.

Yeh-Wei Yu received his BS degree in power mechanical engineering from the National Tsing Hua University in 2003. He received his MS degree and PhD in optical sciences from the National Central University in January 2005 and March 2009, respectively. Now, he is an assistant professor in the Department of Optics and Photonics at the National Central University. His research interests are optical phase conjugational scattering-suppression images, holographic data storage systems, and bidirectional scattering distribution function measurement instruments. 